\title{
Human and animal cystic echinococcosis in Tataouine governorate: hypoendemic area in a hyperendemic country, myth or reality?
}

Selim M'rad ${ }^{1 *}$, Raja Chaâbane-Banaoues ${ }^{1}$, Massaouda Ghrab ${ }^{1}$, Hamouda Babba ${ }^{1,2}$ and Myriam Oudni-M'rad ${ }^{1}$

\begin{abstract}
Background: Cystic echinococcosis (CE) has a worldwide distribution and is especially prevalent in North African countries. With a mean annual surgical incidence (ASI) of CE of 12.7 per 100,000 inhabitants, Tunisia is one of the most CE endemic countries in the Mediterranean area. Tataouine governorate is considered to be the most CE hypoendemic region in Tunisia (ASI = 0.92) despite favourable socioeconomic conditions that enable maintenance of the Echinococcus granulosus sensu lato (s.l.) life-cycle and a significant environmental contamination with E. granulosus s.l. eggs. The aim of this study was to assess human CE seroprevalence, prevalence of CE in food animals and environmental contamination by E. granulosus s.l. eggs in different districts of Tataouine governorate.

Methods: This study was conducted from January to December 2018. A total of 374 human sera samples were tested for the presence of immunoglobulin $\mathrm{G}$ antibodies against E. granulosus using a commercial ELISA kit. Specimens were also collected from animals slaughtered at the Tataouine abattoir $(n=8609)$ and examined for the presence of hydatid cysts; 111 hydatid cysts were genotyped. Eggs of E. granulosus s.l. were identified by PCR and DNA sequencing from dog faecal samples $(n=288)$.
\end{abstract}

Results: Serological tests showed that $8.5 \%$ of the sera samples tested were positive for E. granulosus-specific antibodies. The average prevalence of hydatidosis in livestock was 1.6\%, and CE infection was more prevalent in cattle than in sheep, goats and dromedaries. The contamination rate of dog faeces by E. granulosus sensu stricto eggs varied significantly from 0 to $23.5 \%$ depending on the collection area. Molecular analyses only revealed the presence of the G1 genotype for cysts and eggs.

Conclusions: Based on our findings, CE is likely to be more endemic in the Tataouine governorate than previously described. Thus, to implement an effective control programme against $C E$, a national survey should be carried out to determine human CE prevalence in the different Tunisian governorates.

Keywords: Cystic echinococcosis, Echinococcus granulosus, Epidemiology, Serodiagnosis, Prevalence, Genotyping, Environmental contamination, Humans, Livestock, Dog faeces

\section{Background}

Cystic echinococcosis (CE), also known as hydatidosis, is

\footnotetext{
${ }^{*}$ Correspondence: selim.mrad@gnet.tn

${ }^{1}$ Laboratory of Medical and Molecular Parasitology-Mycology (LP3M),

LR12ES08, Faculty of Pharmacy, University of Monastir, 5000 Monastir, Tunisia

Full list of author information is available at the end of the article
}

a zoonotic disease caused by the larval stage of the species complex Echinococcus granulosus sensu lato (s.l.). $\mathrm{CE}$ has a worldwide distribution and particularly affects poor and pastoral rural communities. Human CE constitutes a severe food-borne parasitic disease listed among the neglected diseases prioritised by the World Health Organization [1]. The annual economic loss due to this disease is estimated at around USD 3 billion worldwide 
[2] and USD 10-19 million in Tunisia [3]. The life-cycle of the parasite requires two hosts: canids as definitive hosts and a wide range of herbivorous or omnivorous animals as intermediate hosts. The adult tapeworm inhabits the small intestine of canids, especially dogs, which release eggs in their faeces. After ingestion by a grazing intermediate host, the viable oncosphere develops into a larval form, or hydatid cyst, mainly in the liver and the lungs. Human infection is due to accidental ingestion of eggs through contaminated vegetables, water, soil and fomites or by direct contact with infected dogs [4]. The liver and the lungs are the most commonly involved organs although many anatomic sites may be affected [5].

Echinococcus granulosus s. $l$. is a complex composed of at least five cryptic species: E. granulosus sensu stricto (s.s) (G1 and G3 genotypes), E. equinus (G4 genotype), E. ortleppi (G5 genotype), E. canadensis (G6-G10 genotypes) and E. felidis [6-9]. Echinococcus granulosus s.l. has a worldwide distribution, but is especially prevalent in North African countries [10, 11]. In Tunisia, E. granulosus s.s. (particularly the G1 genotype) is the most common species associated with human and animal CE [12, 13].

Human diagnosis relies essentially on imaging techniques (ultrasonography, conventional radiography, computerized axial tomography and/or magnetic resonance imaging), and serological tests, such as the enzyme-linked immunosorbent assay (ELISA), indirect haemagglutination assay and immunoblot assay [14]. The classical treatment of human hydatid cyst is surgery, but anthelmintics (albendazole, $10 \mathrm{mg} / \mathrm{kg}$ per day) can be administered in pre- and post-surgical settings [5].

With a mean annual surgical incidence (ASI) of CE of 12.7 per 100,000 inhabitants, Tunisia is one of the most endemic countries in the Mediterranean area [15]. CE is a notifiable disease in Tunisia, and based on the findings of the latest national survey on $\mathrm{CE}$, the 24 governorates (administrative units) were classified as: hyperendemic (ASI > 19), holoendemic $(12.7<\mathrm{ASI}<19)$, mesoendemic $(6.3<\mathrm{ASI}<12.7)$ and hypoendemic regions $(\mathrm{ASI}<6.3)$ [16]. The governorate of Tataouine is currently considered to be the most hypoendemic area for CE in Tunisia $(\mathrm{ASI}=0.92)$. However, two studies conducted on dog faecal samples collected in Tataouine governorate highlighted a high environmental contamination with E. granulosus s.s. eggs $[17,18]$. Thus, it seems relevant to clarify the hypoendemic status of this governorate in such a hyperendemic country as Tunisia. The aim of this epidemiological study was to assess CE human and animal prevalence and environmental contamination by $E$. granulosus s.s. eggs in Tataouine governorate.

\section{Methods}

\section{Study area}

The study was conducted in the governorate of Tataouine, southeastern Tunisia $\left(32^{\circ} 55^{\prime} 40^{\prime \prime} \mathrm{N}, 1026^{\prime} 57^{\prime \prime} \mathrm{E}\right)$, located $531 \mathrm{~km}$ from the capital city of Tunisia (Tunis) (Fig. 1).

Covering an area of about $40,000 \mathrm{~km}^{2}$ (20\% of the total Tunisian area), Tataouine is the largest governorate in Tunisia, with a population of 150,830 inhabitants [19]. The governorate is divided into seven districts (Bir Lahmar, Ghomrassen, Tataouine Nord, Tataouine Sud, Remada, Smâr and Dhiba). It is characterised by a desert climate, with an annual average temperature of $22^{\circ} \mathrm{C}$, summer time temperatures exceeding $40{ }^{\circ} \mathrm{C}$ and an annual rainfall ranging between 88 and $157 \mathrm{~mm}$. Agricultural activities are carried out on $17,000 \mathrm{~km}^{2}$ of Tataouine governorate, with grazing by 5.5 million heads of sheep and goats ( $10 \%$ of the total population) and 25,000 heads of camelids (50\% of the total population) [20].

\section{Sample collection Human samples}

The study was carried out in two stages. In the first stage, we conducted a retrospective study of the medical records of patients who visited the Regional Hospital of Tataouine for consultation for a CE serodiagnosis during a 12-year period (2000-2012). Patients' personal data, such as age, gender and district of origin, were registered. In the second stage, we performed an investigator blind test of CE serological diagnosis on a preexisting collection of human serum samples collected in 2018. All patients included in this investigator blind test were from different districts of Tataouine governorate (Fig. 1). A total of 374 sera samples were collected from these patients at Tataouine Hospital for blood tests (full blood count, erythrocyte sedimentation rate, fasting glucose level) requested for reasons unrelated to CE. For all of these patients, gender and district of origin were listed; age was only recorded for 320 patients (Table 1 ). The patients providing the samples ranged in aged from 1 to 85 years. A serological test for CE diagnosis was performed using a commercial ELISA kit (Ridascreen ${ }^{\circledR}$ Echinococcus IgG ELISA; R-Biopharm, Pfungstad, Germany) following the manufacturer's instructions. Optical density (OD) was measured in a photometer at $450 \mathrm{~nm}$ using a reference wavelength $\geq 620 \mathrm{~nm}$. OD results were used to calculate and interpret a sample index (SI). ELISA results were considered to be positive at $\mathrm{SI} \geq 1.1$, negative at $\mathrm{SI}<0.9$ and equivocal at $0.9 \leq \mathrm{SI}<1.1$. The borderline results were considered to be negative.

\section{Faecal samples}

A total of 284 dog faecal samples were collected between January and December 2018 from six different rural 


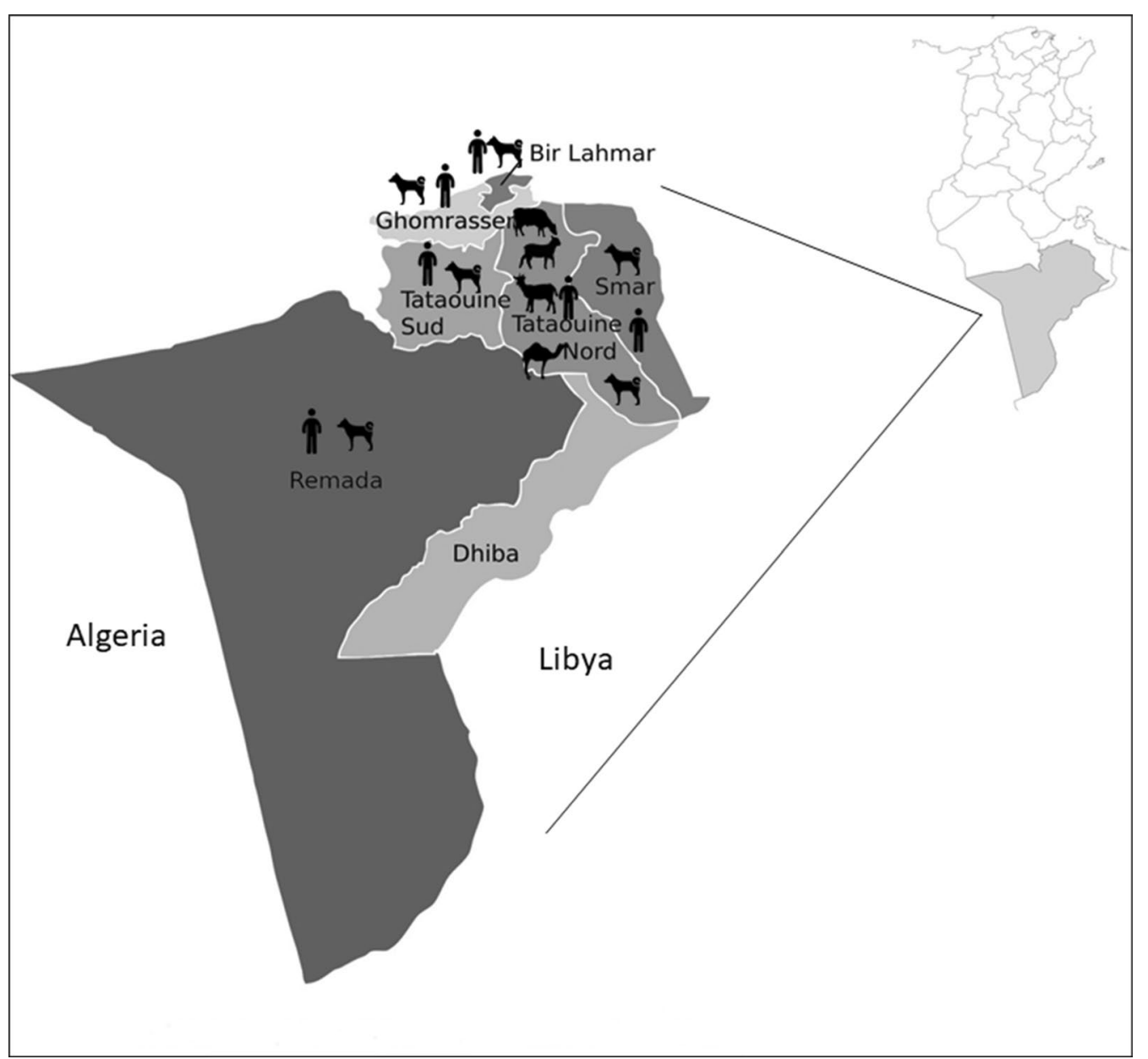

Fig. 1 Locations (districts) in Tataouine governorate where the samples (human sera, dog faeces and livestock cysts) used in this study were collected

and semi-urban districts (Bir Lahmar, Ghomrassen, Tataouine Nord, Tataouine Sud, Remada and Smâr) of Tataouine governorate (Fig. 1). The different collection areas are all in the vicinity of towns, located about 20-40 km apart. The faecal samples of stray and unrestrained dogs were collected from the ground, conserved in a clean plastic container without alcohol or formalin fixation and frozen at $-80{ }^{\circ} \mathrm{C}$ for 7 days to inactivate the infective eggs. For all faecal samples, Taeniidae eggs were concentrated using the sucrose flotation technique as described by Chaâbane-Banaoues et al. [17] and then identified by light microscopic examination [21]. Recovered Taeniidae eggs were indistinguishable from one another by microscopic observation, thus E. granulosus s.s. egg identification was performed by Egss1 PCR assay and cytochrome $c$ oxydase subunit 1 ( $\operatorname{Cox} 1$ ) sequencing. Briefly, DNA was extracted using a phenol/choroform protocol subsequent to an alkaline lysis (dithiothreitol and potassium hydroxide) and an enzymatic digestion by proteinase $\mathrm{K}$ (Invitrogen, Carlsbad, CA, USA) for $1 \mathrm{~h}$ at $56{ }^{\circ} \mathrm{C}$ [17]. The mitochondrial $12 \mathrm{~S}$ rRNA gene was amplified with PCR using the Egss1 primer set specific to the G1 genotype of E. granulosus s.s. [22]. The PCR assay was carried out as previously described by Hizem et al. [23]. The non-amplified Egss1 fragments were re-examined targeting a fragment of the mitochondrial Cox 1 gene by PCR assay according to the procedure described by Gasser et al. [24]. Cox1 PCR products were sequenced and aligned with BLASTn program (https://blast.ncbi.nlm. nih.gov/Blast.cgi).

\section{Livestock samples}

A total of 8609 animals (6622 goats, 1854 sheep, 11 cattle and 122 dromedaries), slaughtered between January and December 2018 at the central abattoir located at Tataouine Nord district (Fig. 1), were examined for the presence of E. granulosus hydatid cyst. A total of 111 hydatid cysts (67 from goats, 30 from sheep, 13 from 
Table 1 Characteristics of patients seropositive for immunoglobulin $\mathrm{G}$ antibodies against Echinococcus granulosus investigated by enzyme-linked immunosorbent assay for cystic echinococcosis in terms of sex, age and district of origin

\begin{tabular}{|c|c|c|c|c|}
\hline \multirow[t]{2}{*}{ Variables } & \multirow[t]{2}{*}{ Groups } & \multicolumn{2}{|l|}{ Seroprevalence } & \multirow[t]{2}{*}{$P$-value } \\
\hline & & Number of examinated patients (\%) & Number of positive patients (\%) & \\
\hline \multirow[t]{3}{*}{ Sex } & Female & $275(73.5)$ & $23(8.4)$ & \multirow[t]{3}{*}{$0.484^{b}$} \\
\hline & Male & $99(26.5)$ & $9(9.1)$ & \\
\hline & Total & $374(100.0)$ & $32(8.6)$ & \\
\hline \multirow[t]{10}{*}{ Age (years) } & $0-9$ & $23(7.2)$ & $2(8.7)$ & \multirow[t]{10}{*}{0.782} \\
\hline & $10-19$ & $34(10.6)$ & $4(11.8)$ & \\
\hline & $20-29$ & $54(16.9)$ & $4(7.4)$ & \\
\hline & $30-39$ & $56(17.5)$ & $5(8.9)$ & \\
\hline & $40-49$ & $41(12.8)$ & $1(2.4)$ & \\
\hline & $50-59$ & $50(15.6)$ & $7(14.0)$ & \\
\hline & $60-69$ & $29(9.1)$ & $2(6.9)$ & \\
\hline & 70-79 & $21(6.6)$ & $1(4.8)$ & \\
\hline & $80-89$ & $12(3.8)$ & $4(33.3)$ & \\
\hline & Total & $320(100.0)$ & $30(9.4)$ & \\
\hline \multirow[t]{7}{*}{ District } & Tataouine Nord & $190(50.8)$ & $19(10.0)$ & \multirow[t]{7}{*}{0.176} \\
\hline & Tataouine Sud & $142(38.0)$ & $11(7.7)$ & \\
\hline & Smâr & $4(1.1)$ & $0(0)$ & \\
\hline & Remada & $28(7.5)$ & $1(3.6)$ & \\
\hline & Bir Lahmar & $3(0.8)$ & $0(0)$ & \\
\hline & Ghomrassen & $7(1.9)$ & $1(14.3)$ & \\
\hline & Total & $374(100.0)$ & $32(8.6)$ & \\
\hline
\end{tabular}

a $P$-value according to Chi-square/Fisher's exact test, as indicated

${ }^{\mathrm{b}}$ Fisher's exact test

cattle and 1 from a dromedary) were collected during meat inspection using visual examination, palpation and systematic incision of the visceral organs. Calcified or degenerated cysts were not considered in the present study. Cyst fertility (presence or absence of protoscoleces) was determined by light microscopic observation. The protoscolex viability was assessed using a vital $0.2 \%$ eosin staining. For 80 cysts ( 45 from goats, 24 from sheep, 10 for cattle, and 1 from a dromedary), DNA was directly extracted from the protoscoleces if present, using the phenol/chloroform protocol [25], or from the germinal layer using a Chelex ${ }^{\circledR}-100$ chelating resin method (BioRad, Hercules, CA, USA). Thus, an isolate refers to the protoscoleces or the germinal layer obtained from a single hydatid cyst. The presence of the G1 genotype of $E$. granulosus s.s. was confirmed using the Egss1 PCR as described in [23].

\section{Statistical analysis}

Qualitative variables were summarized as counts and percentages, and differences were analysed with Fisher's exact test, Chi-square test and two-proportion Z-test, as appropriate, with significance values set at $P<0.05$. The $95 \%$ confidence interval $(95 \% \mathrm{CI})$ was calculated.
Correlation between human serological prevalence (percentage of patients seropositive for $\mathrm{CE}$ ) and environmental infestation indexes (percentage of faecal samples positive for E. granulosus eggs) was assessed using Pearson's correlation. All data analyses were carried out using SPSS ${ }^{\circledR}$ statistical software, version 20 (IBM Corp., Armonk, NY, USA).

\section{Results}

\section{Cystic echinococcosis in humans}

A thorough study of the clinical records of patients consulting for $\mathrm{CE}$ over a 12-year period revealed that only four serological $C E$ diagnoses were requested by the treating doctors. Of these patients, three were seropositive for immunoglobulin $\mathrm{G}$ ( $\operatorname{IgG}$ ) antibodies against $E$. granulosus, a result confirmed by computerized tomography. Two patients were men aged 19 and 78 years who presented with hepatic cysts, and the third was a 47 -yearold woman with a pelvic cyst. They were treated with albendazole, $10 \mathrm{mg} / \mathrm{kg}$ per day, before surgery.

The mean age of the population studied in the investigator blind test was $40 \pm 20.82$ years. A marked predominance of females was noted (73.5 vs 26.5\%). The district 
of origin, age, and gender distribution of patients with $\mathrm{CE}$ are summarized in Table 1.

Serological tests indicated that 32 of the 374 sera samples tested (8.6\%; 95\% CI: 5.7-11.36) were positive for E. granulosus-specific IgG antibodies. The mean age of these seropositive patients was $42 \pm 24.18$ years (Table 1 ). No significant differences in hydatidosis occurrence between females $(8.4 \%)$ and males $(9.1 \%)(P=0.484)$ and between the age groups $\left(\chi^{2}=2.463, d f=8, P=0.782\right)$ were recorded (Table 1). Seropositivity ranged from 0 to $14.3 \%$ depending on the district, with no statistically significant between-district $\left(\chi^{2}=10.595, d f=5, P=0.176\right.$; Table 1).

\section{Faecal sample contamination}

Among the 288 dog faecal samples tested, 37 (12.8\%) were contaminated with taeniid eggs (Table 2). Toxocara spp. (16 isolates) and Trichuris spp. (2 isolates) eggs and protozoan oocysts (5 samples) were also observed (data not shown).

The G1 genotype of E. granulosus s.s. was identified for 32 taeniid egg samples (11.1\%; 95\% CI: 7.7-15.3). For the five remaining isolates, the sequencing products showed 99-100\% homology to T. hydatigena for three faecal isolates (GB accession number \#KT372520.1) and to T. multiceps for two isolates (GB \#LC271734.1) when they were compared against the NCBI database.

The contamination of dog faeces with E. granulosus s.s. eggs varied significantly from 0 to $23.5 \%$ depending on the district $\left(\chi^{2}=16.011, d f=5, P=0.007\right.$ ) (Table 2). The isolates from Remada and Bir Lahmar districts were free of E. granulosus s.s. eggs. Pearson's correlation test revealed no relationship between faecal sample contamination and human seropositivity in the studied districts $(r=-0.181, P=0.720)$.

\section{Cystic echinococcosis in livestock}

During the post-mortem examination, 8609 domestic ruminants were inspected for hydatid disease. Among these, 113 goats, 24 sheep, three cattle and one dromedary harboured one or more cysts with a diameter ranging from 1.5 to $15 \mathrm{~cm}$ (Table 3). The average CE prevalence was $1.6 \%$ (95\% CI: $1.4-1.9)$. The CE prevalence differed significantly between animal species and was more
Table 3 Prevalence of cystic echinococcosis in slaughtered animals during the study period

\begin{tabular}{lrll}
\hline Species & $N$ & $\begin{array}{l}\text { Infected animals, } \\
n(\%)\end{array}$ & $P$-value \\
\hline Goat & 6622 & $113(1.3)$ & $P<0.001$ \\
Sheep & 1854 & $24(1.7)$ & \\
Cattle & 11 & $3(27.3)$ & \\
Dromedary & 122 & $1(0.8)$ & \\
Total & 8609 & $141(1.6)$ & \\
\hline
\end{tabular}

$N$, Number of examined animals; $n$, number of infected animals

a $P$-value (according to Chi-square test)

extensive in cattle (27.3\%; 95\% CI: 6.0-60.9) than in goats (1.7\%; 95\% CI: 1.4-2.0), sheep (1.3\%; 95\% CI:0.8-1.9) and dromedaries (0.8\%; 95\% CI: 0.2-4.4) $\left(\chi^{2}=43.45, d f=3\right.$, $P<0.001$ ) (Table 3).

A greater number of cysts were collected from the liver (56.7\%) than from the lungs (43.2\%) $(Z=1.879, P=0.024)$ (Table 4 ). The mean fertility rate was low (29.7\%) but the cysts from the lungs were more fertile than those from the liver (50 vs 14.3\%, $Z=-3.868, P<0.001$ ) (Table 4). For fertile cysts, the protoscolex viability was estimated to be $80 \%$ (data not shown). The molecular genotyping of the 80 collected cysts (60 infertile and 20 fertile cysts) revealed the presence of only the G1 genotype of E. granulosus s.s.

\section{Discussion}

Despite current preventive control measures (i.e. destruction of contaminated offal and euthanasia of roaming dogs), CE remains a public health concern in Tunisia where the CE endemic status varies from one region to another. In the present study, the serological diagnosis revealed that human CE seroprevalence in Tataouine governorate was significant (8.6\%). This high seroprevalence was unexpected considering the fact that the ASI in Tataouine governorate is the lowest in Tunisia [15] and that only three CE seropositive patients were recorded in our retrospective study over a 12-year period. Moreover, the prevalence reported in the present study was higher than that reported in the neighbouring country of Libya (2.3\%) [26]. Tunisia

Table 2 Distribution of dog faeces contaminated with E. granulosus s.s. eggs according to district

\begin{tabular}{|c|c|c|c|c|c|c|c|c|}
\hline District & Ghomrassen & Tataouine Sud & Tataouine Nord & Remada & Smâr & Bir Lahmar & Total & $P$-value ${ }^{a}$ \\
\hline Total number of faecal samples examined & 80 & 33 & 84 & 28 & 34 & 29 & 288 & \\
\hline Positive for taeniid eggs, $n(\%)$ & $10(12.5)$ & $3(9.1)$ & $16(19)$ & $0(0)$ & $8(23.5)$ & $0(0)$ & $37(12.8)$ & 0.009 \\
\hline $\begin{array}{l}\text { Positive for } \\
\text { E. granulosus (s.s.) eggs, } n(\%)\end{array}$ & $8(10)$ & $2(6)$ & 14 (16.6) & $0(0)$ & $8(23.5)$ & $0(0)$ & $32(11.1)$ & 0.007 \\
\hline
\end{tabular}

${ }^{2} P$-value (according to Chi-square test) 
Table 4 Organ localization and fertility assessment of collected cysts from animals slaughtered in Tataouine governorate during the study period

\begin{tabular}{|c|c|c|c|c|c|c|}
\hline $\begin{array}{l}\text { Organ localization and } \\
\text { fertility assessment }\end{array}$ & Total $(N=111)$ & Goat $(n=67)$ & Sheep $(n=30)$ & Cattle $(n=13)$ & Dromedary $(n=1)$ & $P$-value \\
\hline \multicolumn{7}{|c|}{ Infection according to localization } \\
\hline Liver & $63(56.7)$ & $43(64)$ & $18(60)$ & $1(8)$ & $1(100)$ & 0.024 \\
\hline Lung & $48(43.2)$ & $24(36)$ & $12(40)$ & $12(92)$ & $0(0)$ & \\
\hline \multicolumn{7}{|l|}{ Fertility rate } \\
\hline Fertile & $33(29.7)$ & $16(23.9)$ & $13(43.3)$ & $3(23.1)$ & $1(100)$ & $<0.0001$ \\
\hline Infertile & $78(70.3)$ & $51(76.1)$ & $17(56.7)$ & $10(76.9)$ & $0(0)$ & \\
\hline \multicolumn{7}{|c|}{ Fertility according to localization } \\
\hline Liver & $9(27.3)$ & $3(18.75)$ & $5(38.5)$ & $0(0)$ & $1(100)$ & $<0.0001$ \\
\hline Lung & $24(72.7)$ & $13(81.25)$ & $8(61.5)$ & $3(100)$ & $0(0)$ & \\
\hline
\end{tabular}

Values in the tables are presented as a number with the percentage in parentheses

a $P$-value (according to Z-test)

is a country with a low socioeconomic status, especially in the southern region where it is not always easy to have access to medical follow-up and good quality healthcare. A major proportion of the population of Tataouine governorate lives in rural areas with poor health/hygienic facilities [27]. There is a severe lack of medical facilities in this region; consequently, serological diagnosis of $C E$ and surgery on patients with $C E$ are frequently performed in hospitals in other governorates, which may explain the low serological diagnosis reported here.

No significant relationship between age and CE seroprevalence was noted, although CE is often described as a young adult infection that commonly starts during childhood. Considering that human exposure to E. granulosus s.l. eggs continues throughout life, it is expected that adults might be more exposed than children and have a higher probability of ingesting viable E. granulosus s.l. eggs [4]. Therefore, the difference observed in the present results compared to the national ASI data might be explained by the fact that hydatid cysts grow slowly and may remain asymptomatic for years or decades before triggering clinical symptoms. Moreover, the ASI reported for the Tataouine governorate is outdated and human CE prevalence has very likely changed in the intervening years. Indeed, in the context of the Tunisian post-revolutionary period and the international economic crisis, poverty has risen, hygienic conditions have deteriorated and slaughterhouse control has decreased, all factors facilitating the establishment of the life-cycle of the parasite.

Several studies conducted in Tunisia, Algeria and Libya have reported that women are more commonly affected than men due to the female role in domestic activities, especially in rural areas, and their frequent contact with dogs, soil and vegetables [23, 26, 28, 29]. The absence of significant differences in CE prevalence between men and women in the Tataouine governorate might be attributed to the differences in lifestyle in this region where men are more implicated in agricultural practices and it is rare for women to be in contact with dogs.

Human seroprevalence was not different on the basis of district of origin, and no relationship was observed between human $\mathrm{CE}$ seropositivity and contaminated dog faecal samples, as previously been demonstrated in a large-scale study conducted in seven governorates [17]. The highest percentage of dog faecal samples contaminated with E. granulosus s.s. eggs was found in Smâr; however, CE human seropositivity was one of the lowest at this location. The overall contamination of dog faeces by $E$. granulosus s.s. eggs $(11.1 \%)$ was lower than that reported for the whole country (25.3\%) but similar to that previously described for Tataouine governorate (14.6\%) [17]. These differences in the contamination rate of dog faeces might be due to different canine density and/or total number of tapeworms per dog. In Tunisia, one of the main factors associated with the disease is the density of dogs per square kilometer and per inhabitant, followed by levels of illiteracy in the population, the proportion of households not connected to sewage networks and the proportion of the population in rural areas [16]. Although Chaâbane et al. [18] demonstrated that environmental contamination by E. granulosus s.s. eggs is not related to the presence of slaughterhouses, this is probably not the case in this study where Tataouine Nord, the district containing the largest slaughterhouse in the region, presented one of the highest faecal contamination rates. The numerous E. granulosus s.s. eggs in the 
environment of Tataouine are partly due to poorly and inadequately equipped slaughterhouses, limited economic resources and the absence of efficient waste disposal facilities, as is the case in several North African countries [10, 30, 31]. In this context, and despite the efforts of health authorities, the destruction of contaminated offal is not always implemented, making them easily accessible to free roaming dogs.

On the other hand, home (during cultural and religious celebrations) and uncontrolled (in little roadside restaurants) slaughtering is frequent in Tunisia. Thus, inappropriate human behaviour regarding the management of infected offal and people's unawareness of the risks associated with feeding dogs with such raw viscera also contribute to the maintenance of the life-cycle of E. granulosus s.s. [16, 31, 32]. In Tunisia, the canine population, estimated at about 800,000 dogs, is essentially composed of stray and unrestrained dogs that are often fed with raw discarded offal [33]. In the northern and central regions of the country, the prevalence of E. granulosus s.s. in dogs varies between 5 and $21 \%$, with the total number of tapeworms per dog ranging from 2 to 2540 [34, 35], resulting in a massive dissemination of E. granulosus s.s. eggs into the environment. At a larger scale, studies performed in neighbouring countries, such as Algeria and Libya, demonstrated a similar prevalence of E. granulosus s.l. in necropsied dogs of 16 and 16.1\% (range: 6.7-22.5\%), respectively [36, 37]. Unfortunately, no investigation into the prevalence in dogs was carried out in the Tataouine governorate. Nevertheless, even though the prevalence of E. granulosus s.s. in dogs is lower than that in other governorates, the eggs remain viable over months to years and remain a risk for public health.

The CE prevalence in slaughtered livestock recorded here is low (1.6\%) and similar to that reported in 2017 (1.7\%) in the Tataouine governorate by the Regional Commissary for Agricultural Development of the Tataouine Governorate. This prevalence varied considerably depending on the animal species. Except for cattle, the prevalence was lower than that reported in the other governorates of Tunisia where E. granulosus s.s. infection ranged from 16.42 to $40.42 \%$ in sheep and was $8.5 \%$ in cattle, $6 \%$ in dromedaries and $2.9 \%$ in goats [38, 39]. Tunisia is a country with a past and current history of pastoral husbandry, especially in the southern regions where traditional livestock breeding systems are based on the use of large rangelands [20]. The differences in prevalence observed in the present study might have been influenced by the level of environmental contamination by E. granulosus s.s. eggs and the climatic conditions (low rainfall and high temperature in summer) that reduce the viability of eggs [40], but also by livestock age at slaughter. It is known that the E. granulosus s.l. contamination is higher in older than in younger animals because older animals have been more exposed to E. granulosus s.l. eggs throughout their life [39]. It is possible that livestock in Tataouine governorate are slaughtered at a younger age compared other governorates, but no data on the age of the slaughtered animals were available for the present study.

Even if CE animal prevalence is relatively low, this does not prevent the maintenance of the life-cycle. A recent survey was conducted in India over a 7-year period to determine the prevalence of $\mathrm{CE}$ in slaughtered animals, in dogs and in humans [41]. The study demonstrated that despite low infestation rates ranging from 0.01 to $3.00 \%$ in livestock and no more than $4.34 \%$ in dog faeces, a high CE human seroprevalence (11\%) was present.

Contrary to other governorates where sheep is the most consumed animal [39], in Tataouine governorate the goat is the most commonly slaughtered animal. As reported in several studies, goats seem to be less frequently infected than sheep, cattle and dromedaries, and a weak CE infection of goats was described in the northern governorates of Tunisia (2.9\%, $n=3779)$ [39], Algeria $(0 \%, n=37)$ [42] and Morocco $(1.88 \%, n=2337)$ [43]. This lower infection rate might result from goats' feeding behaviour which consists mostly of grazing on bushes and tree branches, making them less exposed to the ingestion of E. granulosus s.s. eggs.

In Tunisia, the G1 genotype of E. granulosus s.s. remains the prevailing genotype involved in animal $\mathrm{CE}$, and only some studies have reported genotype G6 in camel infections [12, 13, 44]. This finding is similar to that reported in Maghreb countries, such as Algeria, Libya and Morocco, where CE transmission essentially implies a domestic life-cycle involving dogs and livestock (reviewed in Deplazes [11]). The predominance of the G1 genotype in Tunisia could be related to its probable role in its dissemination in neighbouring and distant countries. The authors of a recent study carried out on the near-complete mitochondrial genome sequences argue that Tunisia might be one of ancestral locations of the G1 genotype and possibly be responsible for several diffusion routes of the G1 E. granulosus s.s. to Algeria and Morocco via the dispersal of domesticated animals, and to Argentina, Australia and Turkey via human and livestock migration [45].

The main limitation of this study is that diagnosis was restricted to a blind investigator ELISA test in the absence of imagery to confirm results. Due to the retrospective nature of the work, data retrieval was very challenging, and there was no system in place that enabled us to contact $\mathrm{CE}$ seropositive patients and to confirm our serological results by imagery. Moreover, the ELISA commercial kit that was used can detect not only IgG 
antibodies against E. granulosus but also those against E. multilocularis, which raises the possibility of potential false positive results. Nevertheless, since only two human alveolar echinococcosis cases have been reported over the last 35 years in Tunisia, it is quite unlikely to have had an impact on our results $[46,47]$. The manufacturer has also reported cross-reactions with Taenia solium antigens. Nonetheless, with Tunisia being a Muslim country, it is unlikely that $T$. solium, which needs pigs as intermediate hosts, can complete its life-cycle in Tunisia.

\section{Conclusions}

The findings of this study demonstrate that human CE infection and environmental contamination by E. granulosus s.s. eggs are high in a governorate considered to be hypoendemic for CE. The Tataouine governorate is probably more endemic for $\mathrm{CE}$ than previously described, and there seems to be an existing socioeconomic situation that is favourable for cystic echinococcosis transmission in this governorate. There are numerous social factors favouring the maintenance of the E. granulosus s.s. lifecycle, such as poor public awareness of $\mathrm{CE}$, home slaughter of livestock, improper and uncontrolled disposal of infected viscera and frequent exposure of stray dogs by $E$. granulosus s.s. contaminated offal.

To better understand the CE epidemiological situation in the Tataouine governorate, especially for humans, further investigations, including prospective serological studies combined with medical imagery, are needed. To implement an effective control programme against CE, a national survey conducted on humans, livestock and dogs should be carried out in order to better assess the $\mathrm{CE}$ endemic status of the different Tunisian governorates.

\section{Abbreviations \\ ASI: Mean annual surgical incidence; CE: Cystic echinococcosis; 95\% Cl: 95\% Confidence intervals; Cox 1: Cytochrome c oxydase subunit 1; ELISA: Enzyme- linked immunosorbent assay; OD: Optical density; SI: Sample index.}

\section{Acknowledgements}

The authors are grateful to Mohsen Bouajila (Municipal slaughterhouse of Tataouine) for collecting the animal cyst samples. We express our gratitude to the following members from the regional hospital of Tataouine for providing human sera samples: Massoud Mhamdi, Abdallah Ghrab and Khaled Almadani. The authors also wish to thank Nedra Kerkeni (High Institute of Biotechnology of Monastir, Tunisia) and Moncef Rassas (Faculty of Medicine of Monastir, Tunisia) for their assistance with the linguistic aspect of this paper.

\section{Authors' contributions}

SM designed the study, contributed to the data collection, performed data analysis and drafted the manuscript. RCB performed data analysis and contributed to drafting op the manuscript. MG contributed to the data collection and performed data analysis. $\mathrm{HB}$ designed the study and revised critically the manuscript. MOM designed the study, contributed to the acquisition of data collection, performed data analysis and drafted the manuscript. All authors read and approved the final manuscript.

\section{Funding}

This study was funded by the Tunisian Ministry of Higher Education and Scientific Research. The funding source is not involved in the study design, in the collection, analysis and interpretation of data, in the writing of the report, and in the decision to submit the article for publication.

\section{Availability of data and materials}

The datasets used and/or analyzed during the current study are available from the corresponding author on reasonable request.

\section{Declarations}

\section{Ethics approval and consent to participate}

The study was carried out according to the Declaration of Helsinki Principles and all Tunisian pertinent regulations. The Ethics Committee of the High Institute of Biotechnology of Monastir (ISBM, Tunisia) validated the sampling procedures and the design of the study. Human serum samples were derived from a pre-existing collection of sera at the Tataouine Regional Hospital (Tunisia). The cyst samples from animals were collected during post-mortem examination, with the due consent of the veterinary officer, within the framework of governmentally regulated meat inspections in Tataouine slaughterhouses.

\section{Competing interests}

The authors declare that they have no competing interests.

\section{Consent for publication}

Not applicable.

\section{Author details}

${ }^{1}$ Laboratory of Medical and Molecular Parasitology-Mycology (LP3M), LR12ES08, Faculty of Pharmacy, University of Monastir, 5000 Monastir, Tunisia. ${ }^{2}$ Laboratory of Parasitology-Mycology, EPS F. Bourguiba, 5000 Monastir, Tunisia.

Received: 11 June 2020 Accepted: 1 April 2021

Published online: 21 April 2021

\section{References}

1. FAO/WHO. Multicriteria-based ranking for risk management of foodborne parasites. Microbiological Risk Assessment Series No. 23. Rome: Food and Agriculture Organization of the United Nations/World Health Organization, 2014. https://apps.who.int/iris/bitstream/handle/10665/ 112672/9789241564700_eng.pdf?sequence=1. Accessed 05 Jan 2021.

2. WHO. Echinococcosis fact sheet. Geneva: World Health Organization, 2020. https://www.who.int/news-room/fact-sheets/detail/echinococc osis. Accessed 05 Jan 2021.

3. Majorowski MM, Carabin H, Kilani M, Bensalah A. Echinococcosis in Tunisia: a cost analysis. Trans R Soc Trop Med Hyg. 2005;99:268-78.

4. Tamarozzi F, Deplazes P, Casulli A. Reinventing the wheel of Echinococcus granulosus sensu lato transmission to Humans. Trends Parasitol. 2020;36:427-34.

5. Wen H, Vuitton L, Tuxun T, Li J, Vuitton DA, Zhang W, et al. Echinococcosis: advances in the 21st Century. Clin Microbiol Rev. 2019;32:e00075-e118.

6. Nakao M, Li T, Han X, Ma X, Xiao N, Qiu J, et al. Genetic polymorphisms of Echinococcus tapeworms in China as determined by mitochondrial and nuclear DNA sequences. Int J Parasitol. 2010;40:379-85.

7. Nakao M, McManus DP, Schantz PM, Craig PS, Ito A. A molecular phylogeny of the genus Echinococcus inferred from complete mitochondrial genomes. Parasitology. 2007;134:713-22.

8. Hüttner M, Nakao M, Wassermann T, Siefert L, Boomker JDF, Dinkel A, et al Genetic characterization and phylogenetic position of Echinococcus felidis Ortlepp, 1937 (Cestoda: Taeniidae) from the African lion. Int J Parasitol. 2008;38:861-8.

9. Romig T, Ebi D, Wassermann M. Taxonomy and molecular epidemiology of Echinococcus granulosus sensu lato. Vet parasitol. 2015;213:76-84.

10. Dakkak A. Echinococcosis/hydatidosis: a severe threat in Mediterranean countries. Vet Parasitol. 2010;174:2-11. 
11. Deplazes P, Rinaldi L, Alvarez Rojas CA, Torgerson PR, Harandi MF, Romig T, et al. Global distribution of alveolar and cystic echinococcosis. Adv Parasitol. 2017;95:315-493.

12. Boufana B, Lahmar S, Rebai W, Ben Safta Z, Jebabli L, Ammar A, et al. Genetic variability and haplotypes of Echinococcus isolates from Tunisia. Trans R Soc Trop Med Hyg. 2014;108:706-14.

13. Oudni-M'rad M, M'rad S, Babba H. Molecular and epidemiology data on cystic echinococcosis in Tunisia. In: Current topics in echinococcosis. London: InTech; 2015. p. 56-74.

14. Kern P, Menezes da Silva A, Akhan O, Müllhaupt B, Vizcaychipi KA, Budke $C$, et al. The echinococcoses: diagnosis, clinical management and burden of disease. Adv Parasitol. 2017;96:259-369.

15. Chahed MK, Bellali H, Touini H, Cherif R, Ben Safta Z, Essoussi M, et al. L'incidence chirurgicale du kyste hydatique en Tunisie: résultats de l'enquête 2001-2005 et tendance évolutive entre 1977-2005. Arch Inst Pasteur Tunis. 2010;87:43-52.

16. Chahed MK, Bellali H, Ben Alaya N, Aoun K, Zouari B. High risk areas for echinococcosis-hydatidosis in Tunisia. Tunis Med. 2015;93:33-7.

17. Chaâbane-Banaoues R, Oudni-M'rad M, Cabaret J, M'rad S, Mezhoud H, Babba H. Infection of dogs with Echinococcus granulosus: causes and consequences in an hyperendemic area. Parasit Vectors. 2015;8:231.

18. Chaâbane-Banaoues R, Oudni-M'rad M, M'rad S, Mezhoud H, Babba H. Environmental contamination by Echinococcus granulosus sensu lato eggs in relation to slaughterhouses in urban and rural areas in Tunisia. Korean J Parasitol. 2016;54(1):113-8.

19. Ministry of Development Investment and International Cooperation. Gouvernorat de Tataouine en chiffres. 2019. http://www.ods.nat.tn/ upload/CHIFTATAOUINE. Accessed 05 Jan 2021

20. Ammar H, Bodas R, Ben Younes M, López S. Goat breeding systems in the south of Tunisia (Tataouine). In : Bernués A, Boutonnet JP, Casasús I, Chentouf M, Gabiña D, Joy M, López-Francos A, Morand-Fehr P, Pacheco $F$, editors. Economic, social and environmental sustainability in sheep and goat production systems. Zaragoza: CIHEAM/FAO/CITADGA; 2011. p. 283-8.

21. Mehlhorn H. Encyclopedia of parasitology. Berlin Heidelberg: Springer; 2008.

22. Dinkel A, Njoroge EM, Zimmermann A, Walz M, Zeyhle E, Elmahdi IE, et al. A PCR system for detection of species and genotypes of the Echinococcus granulosus-complex, with reference to the epidemiological situation in eastern Africa. Int J Parasitol. 2004;34:645-53.

23. Hizem A, M'rad S, Oudni-M'rad M, Mestiri S, Hammedi F, Mezhoud H, et al. Molecular genotyping of Echinococcus granulosus using formalin-fixed paraffin-embedded preparations from human isolates in unusual tissue sites. J Helminthol. 2015;2015:1-5.

24. Gasser RB, Zhu X, McManus DP. Dideoxy fingerprinting: application to the genotyping of Echinococcus. Int J Parasitol. 1998;28:1775-9.

25. Sambrook J, Fritsch EF, Maniatis T. Molecular cloning: a laboratory manual. New York: Cold Spring Harbor Laboratory Press; 1989.

26. Bernawi AAA, Ayed NB, Allaa AHME, Khalil EAG. Sero-prevalence and exposure rates of humans to Echinococcus granulosus infection in southern libya. Int J Curr Res. 2015;7:20392-6.

27. Ministry of Regional Development and Planning. Gouvernorat de Tataouine: L'indicateur de développement régional-Pointer les difficultés pour orienter les efforts et suivre le progrès. 2012. http://www.mpci.gov. tn/tn/Gov/indica/Tataouine.pdf. Accessed 05 Jan 2021.

28. M'rad S, Oudni-M'rad M, Boubaker G, Bouazzi L, Gorcii M, Nouri A, et al. Retrospective study of the distribution and the fertility of hydatid cysts in the child in Tunisia. Patholog Biol. 2012;60:166-9.

29. Zait H, Achir I, Guerchani MK, Hamrioui B. Profil épidémiologique de 290 cas d'échinococcose kystique humaine diagnostiqués au CHU Mustapha d'Alger (2006 à 2011). Pathol Biol. 2013;61:193-8.

30. Thys S, Sahibi H, Gabriel S, Rahali T, Lefevre P, Rhalem A, et al. Community perception and knowledge of cystic echinococcosis in the High Atlas Mountains, Morocco. BMC Public Health. 2019:19:118.
31. El Berbri I, Ducrotoy MJ, Petavy AF, Fassifihri O, Shaw AP, Bouslikhane M, et al. Knowledge, attitudes and practices with regard to the presence, transmission, impact, and control of cystic echinococcosis in Sidi Kacem Province, Morocco. Infect Dis Poverty. 2015;4:48.

32. Besbes M, Sellami H, Cheikhrouhou F, Makni F, Ayadi A. Clandestine slaughtering in Tunisia: investigation on the knowledge and practices of butchers concerning hydatidosis. Bull Soc Pathol Exot. 1990;2003(96):320-2.

33. Aoun K, Bouratbine A. Epidemiological data concerning hydatidosis in Tunisia. Med Mal Infect. 2007;37:S40-2.

34. Lahmar S, Arfa I, Ben Othmen S, Jguirim W, Saïd Y, Dhibi A, et al. Intestinal helminths of stray dogs from Tunisia with special reference to zoonotic infections. Parasitol Open. 2017;3:e18.

35. Lahmar S, Kilani M, Torgerson PR. Frequency distributions of Echinococcus granulosus and other helminths in stray dogs in Tunisia. Ann Trop Med Parasitol. 2001;95:69-76.

36. Bentounsi B, Meradi S, Ayachi A, Cabaret J. Cestodes of untreated large stray dog populations in Algeria: a reservoir for herbivore and human parasitic diseases. Tovsj. 2009;3:64-7.

37. Buishi IE, Njoroge EM, Bouamra O, Craig PS. Canine echinococcosis in northwest Libya: assessment of coproantigen ELISA, and a survey of infection with analysis of risk-factors. Vet Parasitol. 2005;130:223-32.

38. Lahmar S, Debbek H, Zhang LH, McManus DP, Souissi A, Chelly S, et al. Transmission dynamics of the Echinococcus granulosus sheep-dog strain (G1 genotype) in camels in Tunisia. Vet Parasitol. 2004;121:151-6.

39. Lahmar S, Trifi M, Ben Naceur S, Bouchhima T, Lahouar N, Lamouchi I, et al. Cystic echinococcosis in slaughtered domestic ruminants from Tunisia. J Helminthol. 2013;87:318-25.

40. Sanchez Thevenet $P$, Alvarez HM, Torrecillas $C$, Jensen O, Basualdo JA. Dispersion of Echinococcus granulosus eggs from infected dogs under natural conditions in Patagonia, Argentina. J Helminthol. 2019;94:e29.

41. Vaidya VM, Zende RJ, Paturkar AM, Gatne ML, Dighe DG, Waghmare RN, et al. Cystic echinococcosis in animals and humans of Maharashtra State, India. Acta Parasitol. 2018;63:232-43.

42. Laatamna AE, Ebi D, Brahimi K, Bediaf K, Wassermann M, Souttou K, et al. Frequency and genetic diversity of Echinococcus granulosus sensu stricto in sheep and cattle from the steppe region of Djelfa, Algeria. Parasitol Res. 2019;118:89-96.

43. Azlaf R, Dakkak A. Epidemiological study of the cystic echinococcosis in Morocco. Vet Parasitol. 2006;137:83-93.

44. Mrad S, Filisetti D, Oudni M, Mekki M, Belguith M, Nouri A, et al. Molecular evidence of ovine (G1) and camel (G6) strains of Echinococcus granulosus in Tunisia and putative role of cattle in human contamination. Vet Parasitol. 2005;129(3-4):267-72.

45. Kinkar L, Laurimae T, Acosta-Jamett G, Andresiuk V, Balkaya I, Casulli A, et al. Global phylogeography and genetic diversity of the zoonotic tapeworm Echinococcus granulosus sensu stricto genotype G1. Int J Parasitol. 2018;48:729-42.

46. Robbana M, Ben Rachid MS, Zitouna MM, Heldt N, Hafsia M. Première observation d'échinococcose alvéolaire autochtone en Tunisie. Arch Anat Cytol Path. 1981;29:311-2.

47. Zitouna MM, Boubaker S, Dallagi K, Ben Safta Z, Hadj Salah H, Robbana $\mathrm{M}$, et al. Alveolar echinococcosis in Tunisia. A propos of 2 cases. Bull Soc Pathol Exot. 1985;78:723-8.

\section{Publisher's Note}

Springer Nature remains neutral with regard to jurisdictional claims in published maps and institutional affiliations. 